\title{
Seasonal fluctuation in zooxanthellar genotype composition and photophysiology in the corals Pavona divaricata and $P$. decussata
}

\author{
Ryota Suwa $^{1}$, Mamiko Hirose ${ }^{2}$, Michio Hidaka ${ }^{2, *}$ \\ ${ }^{1}$ Department of Marine and Environmental Science, Graduate School of Engineering and Science, University of the Ryukyus, \\ Nishihara, Okinawa 903-0213, Japan \\ ${ }^{2}$ Department of Chemistry, Biology and Marine Sciences, Faculty of Science, University of the Ryukyus, Nishihara, \\ Okinawa 903-0213, Japan
}

\begin{abstract}
We simultaneously examined seasonal fluctuations in maximum quantum yield $\left(F_{\mathrm{v}} / F_{\mathrm{m}}\right)$ cell density and genotypic clade composition of zooxanthellae in the sympatric corals Pavona divaricata and $P$. decussata at a high latitude site in Okinawa, Japan. The 2 species had different responses to seasonal changes in light and seawater temperature. P. decussata was associated only with clade C zooxanthellae (at all sampling times) while genotypic clade composition fluctuated in P. divaricata. Three colonies of $P$. divaricata harbored clade D throughout the year and the other 7 colonies changed clade type from $C$ to $D$ or vice versa, or contained a mixture of both clades on some sampling occasions. Though neither coral species suffered bleaching during the experimental period, there were $F_{\mathrm{v}} / F_{\mathrm{m}}$ decreases in $P$. decussata and $P$. divaricata harboring clade $\mathrm{C}$ during cold and warm seasons; $F_{\mathrm{v}} / F_{\mathrm{m}}$ of $P$. divaricata harboring clade D was stable. When exposed to low or high temperature under normal or high light, $P$. divaricata harboring clade D was less damaged and Photosystem II recovery was faster than in $P$. decussata harboring clade $C$. These results suggest that the sympatric congeneric corals have different symbiont switching flexibilities and this difference might account for the observed difference in stress susceptibility between the two species. In high-latitude reefs, both winter low temperatures and summer high temperatures may be potential stressors that cause coral bleaching, at least in corals with high clade $\mathrm{C}$ zooxanthellar fidelity.
\end{abstract}

KEY WORDS: Corals $\cdot$ Bleaching $\cdot$ Zooxanthellae $\cdot$ Clade $\cdot$ Flexibility $\cdot$ Okinawa $\cdot$ High latitude

\section{INTRODUCTION}

Large-scale coral bleaching has been reported over the past 2 decades (Hoegh-Guldberg 1999). Coral bleaching results from loss of symbiotic dinoflagellates (zooxanthellae) and/or their photosynthetic pigments (Glynn \& D'Croz 1990, Lesser et al. 1990) and may lead to mortality of corals (Glynn 1988). While various environmental stresses cause coral bleaching, large-scale bleaching is generally ascribed to elevated sea surface temperature (e.g. Hoegh-Guldberg 1999). Corals become bleached when seawater temperature increases by 1 to $2^{\circ} \mathrm{C}$ above the annual maximum temperature
(Hoegh-Guldberg 1999). Although the mechanism of coral bleaching is not well understood, one possibility is that elevated oxygen stress due to thermal inactivation of the carbon fixation cycle and Photosystem II (PS II) function causes damage to zooxanthellae (Lesser 1996) as well as to the coral host. Coral host cells may expel their symbionts as a protective mechanism against reactive oxygen species (Lesser 1997, Suwa \& Hidaka 2006), or they may rupture, and thus release algal cells (Glynn et al. 1985).

Various environmental stressors are known to induce coral bleaching in addition to high temperature (Fitt \& Warner 1995), viz. low temperature (Saxby et al. 
2003, Hoegh-Guldberg et al. 2005), high levels of solar radiation (Warner et al. 1999), ultraviolet radiation (Lesser et al. 1990), low salinity (Kerswell \& Jones 2003), and herbicides (Jones \& Kerswell 2003). The maximum quantum yield of PS II $\left(F_{\mathrm{v}} / F_{\mathrm{m}}\right)$ measured by pulse amplitude modulated (PAM) fluorometry has been widely used as a tool to estimate the effect of various environmental stresses on the photosynthetic apparatus of various organisms. In corals, $F_{\mathrm{v}} / F_{\mathrm{m}}$ decline precedes coral bleaching (Jones \& HoeghGuldberg 2001, Lesser \& Gorbunov 2001, Warner et al. 2002). Warner et al. (2002) reported that in Montastraea, a $F_{\mathrm{v}} / F_{\mathrm{m}}$ value lower than the monthly mean occurred in the summer of a coral bleaching year. Winters et al. (2006) pointed out that the seasonal fluctuation in $F_{\mathrm{v}} / F_{\mathrm{m}}$ should be considered when coral bleaching is assessed using PAM fluorometry. The global distribution of coral reefs generally coincides with the $18^{\circ} \mathrm{C}$ monthly lower seawater isotherm (Buddemeier et al. 2004), and coral populations at high latitudes are thought to suffer cold temperature stress (Coles \& Jokiel 1977, Nakamura et al. 2003, Saxby et al. 2003). However, $F_{\mathrm{v}} / F_{\mathrm{m}}$ seasonal fluctuations have not been documented previously for high-latitude coral reefs.

Zooxanthellae are classified into 8 clades (A to $\mathrm{H}$ ) based on restriction fragment length polymorphism (RFLP) analysis or the sequence of rRNA encoding genes (Pochon et al. 2004). Zooxanthellae belonging to different clades have different physiological responses to environmental changes (Rowan 2004, Berkelmans \& van Oppen 2006); moreover, physiological characteristics can also vary within zooxanthellae belonging to the same genotypic clade (Tchernov et al. 2004). While molecular studies have revealed the genetic diversity of zooxanthellae, ecological or physiological roles of the genotypes are still not well understood. The genotypic composition of zooxanthellae in a single colony may also fluctuate seasonally with or without a particular perturbation (Chen et al. 2005, Thornhill et al. 2006). However, there is no study that simultaneously describes seasonal changes in photophysiology and zooxanthellar clade composition in corals. We tracked the seasonal fluctuation in physiological characteristics and genotypic composition of zooxanthellae in the 2 sympatric coral species Pavona divaricata and $P$. decussata on a high-latitude reef; restricting the study to a single reef allowed us to rule out geographic variation as a factor. We investigated the physiological responses of corals to seasonal changes in environmental conditions by measuring $F_{\mathrm{v}} / F_{\mathrm{m}}$ values, zooxanthellar density and genotypic clade composition over 1 yr. Since the 2 coral species studied had different symbiont switching flexibilities (1 with high fidelity to 1 clade type and the other with high flexibility), artificial stress-exposure experiments were conducted to compare tolerances of the 2 corals.

\section{MATERIALS AND METHODS}

Study site and coral collection. Colonies of Pavona divaricata and $P$. decussata inhabit a shallow water lagoon (0.5 to $1.0 \mathrm{~m}$ depth) at the study site (Bise) on the northern part of Okinawa Island, Japan $\left(26^{\circ} 42^{\prime} \mathrm{N}\right.$, $127^{\circ} 52^{\prime}$ E). Fragments from 10 tagged colonies of each species were collected by snorkeling monthly from January 2005 to January 2006. Three fragments were collected midway along the vertical axis of each colony to minimize effects of intra-colonial variability. The samples collected were immediately taken to Sesoko Station, Tropical Biosphere Research Center, University of the Ryukyus, $8 \mathrm{~km}$ away. On the day following collection, 1 fragment from each colony was immersed in a $2: 1$ mixture of $20 \%$ acetic acid and $10 \%$ formalin in filtered seawater for later measurement of zooxanthellar density. The second fragment was preserved in a guanidine solution (4 M guanidine thiocyanate, $0.1 \%$ sodium N-lauroylsarcosinate, $25 \mathrm{mM}$ Tris- $\mathrm{HCl}$ (pH 8.0), $0.1 \mathrm{M}$ 2-mercaptoethanol) for later identification of zooxanthellar clades. For photophysiological measurements, the third fragment was kept in an indoor tank supplied with unfiltered seawater. The tank was exposed to sunlight through glass roof windows. In some months, fragments from one or two colonies were lost, and analysis was done on 8 or 9 samples.

In addition to the monthly collection described above, samples were collected from the middle parts of 5 untagged colonies of both species on February 2005 and May 2006 for stress experiments. Small fragments were fixed on glass slides with a rubber band and were allowed to recover for $2 \mathrm{wk}$ in the running seawater tank prior to the stress treatments.

Photochemical efficiency of algal PSII. Seasonal variability in algal PSII photochemical efficiency was investigated using a PAM fluorometer (MINI-PAM, Walz). Fragments of the corals were removed from the indoor tank and inserted in a custom-made acrylic black box filled with filtered $(0.45 \mu \mathrm{m})$ seawater. The fiber optical probe $(5.5 \mathrm{~mm}$ in diameter) of the PAM was inserted through a hole in the top of the box. The distance between the tip of the probe and each sample was adjusted to $1 \mathrm{~cm}$ by stacking glass slides below the samples. The photochemical efficiency $\left(F_{\mathrm{v}} / F_{\mathrm{m}}\right)$ of PSII was measured after a 15 min dark-adaptation period. The initial fluorescence $\left(F_{0}\right)$ was measured by applying pulses of weak red light $\left(<1 \mu \mathrm{mol}\right.$ photons $\left.\mathrm{m}^{-2} \mathrm{~s}^{-1}\right)$, and a saturating pulse $\left(8000 \mu \mathrm{mol}\right.$ photons $\mathrm{m}^{-2} \mathrm{~s}^{-1}, 0.8 \mathrm{~s}$ duration) was applied to determine the maximal fluorescence $\left(F_{\mathrm{m}}\right)$. The ratio of the change in fluorescence $\left(F_{\mathrm{v}}=F_{\mathrm{m}}-F_{0}\right)$ caused by the saturating pulse to $F_{\mathrm{m}}$ is a good measure of maximum quantum yield of PSII (Genty et al. 1989). Measurements of dark-adapted 
$F_{\mathrm{v}} / F_{\mathrm{m}}$ were conducted in the morning (08:00 to $\left.10: 00 \mathrm{~h}\right)$ following the day of collection since $F_{\mathrm{v}} / F_{\mathrm{m}}$ in corals is known to change diurnally (Jones \& Hoegh-Guldberg 2001). The indoor tank was shaded with an $84 \%$-shading mesh until measurements were taken to keep the light intensity in the tank below $100 \mu \mathrm{mol}$ photons $\mathrm{m}^{-2} \mathrm{~s}^{-1}$.

Zooxanthellar density. To measure the densities in coral fragments, pieces were immersed in a 2:1 mixture of $20 \%$ acetic acid and $10 \%$ formalin for several days to decalcify. Afterwards, coral tissues were homogenized using a Potter homogenizer and replicate counts $(n=8)$ of zooxanthellae were made using a hemocytometer. Because the fragments used were plate-like in both corals, the projected areas were obtained from 2-dimensional photoimages using Scion Image Software (Scion). The surface areas of the fragments were calculated by doubling the projected areas.

RFLP analysis of zooxanthellar clade. Fragments of coral were crushed with pliers and immersed in a guanidine solution as described above. Dissolved coral solutions were diluted with $2 \times$ CTAB solution $(4 \%$ cethyl trimethyl ammonium bromide; $100 \mathrm{mM}$ Tris$\mathrm{HCl}, \mathrm{pH} 8.0 ; 1.4 \mathrm{M} \mathrm{NaCl}$ ) and incubated at $65^{\circ} \mathrm{C}$ for $1 \mathrm{~h}$. DNA was extracted twice with phenol/chloroformisoamylalcohol and subsequently once with chloroform-isoamylalcohol. Extracted DNA was then diluted with $3 \mathrm{M} \mathrm{NaOAC}$ ( $\mathrm{pH}$ 5.2) and isopropanol was added to the solution. The solution was held at $-20^{\circ} \mathrm{C}$ for 30 min. Pellets of DNA were collected by centrifugation, washed with $70 \%$ ethanol and dried with an aspirator before dissolution in TE buffer [10 mM Tris- $\mathrm{HCl}_{\text {; }}$ 1 mM EDTA, pH 8.0].

PCR amplifications of algal 18S-rDNA and 28S-rDNA were performed in a TP-400 PCR Thermal Cycler SP (TaKaRa) or in a Mastercycler ep (Eppendorf) using Taq polymerase (TaKaRa). 18S-rDNA was amplified using the zooxanthella-specific primer pair ss5z (5'-GCA GTT ATA (A/G)TT TAT TTG ATG GT(C/T) (A/G)CT GCT AC-3') and ss3z (5'-AGC ACT GCG TCA GTC CGA ATA ATT CAC CGG-3') (Rowan \& Powers 1991). PCR amplification of 28S-rDNA was performed with the zooxanthella-specific primer pair lsu-UFP1 (5'-CCC GCTAAT TTA AGCATATAA GTA-3') and lsu-URP1 (5'-GTTAGA CTCCTT GGT CGT GTT TCA-3') (Zardoya et al. 1995). PCR products were digested using the restriction enzyme TaqI and electrophoresed in a $4 \%$ agarose gel. Zooxanthellar clade identification was based on the band pattern of digested 18S-rDNA fragments (Rowan \& Powers 1991, Santos et al. 2002). When clade C and D zooxanthellae appeared to occur in one sample, the presence of clade D was confirmed by RFLP analysis of 28S-rDNA.

Environmental data. Seawater temperature at Bise ( 0.5 to $1.0 \mathrm{~m}$ ) was recorded every second hour using data loggers (HOBO Water Temp Pro, Onset). Data on monthly average total daily solar radiation $\left(\mathrm{MJ} \mathrm{m}^{-2} \mathrm{~d}^{-1}\right)$ were obtained from Okinawa Meteorological Observatory at Naha, Okinawa.

Stress experiments. Photophysiological responses of the corals to elevated temperature $\left(33^{\circ} \mathrm{C}, \mathrm{HT}\right)$ or decreased temperature $\left(18^{\circ} \mathrm{C}, \mathrm{LT}\right)$ were investigated in February 2005 and in May 2006, respectively. Coral fragments were placed in glass aquaria (57 l) regulated at 2 temperatures, normal $\left(26^{\circ} \mathrm{C}, \mathrm{NT}\right)$ and high $(\mathrm{HT})$, or normal and low (LT) temperatures under 2 light intensities: low (100 $\mu \mathrm{mol}$ photons $\mathrm{m}^{-2} \mathrm{~s}^{-1}$, LL) or high (1000 $\mu \mathrm{mol}$ photons $\mathrm{m}^{-2} \mathrm{~s}^{-1}$, HL) light. The aquaria were filled with $0.45 \mu \mathrm{m}$-filtered seawater, which was agitated by aeration. After $3 \mathrm{~h}$ exposure to different temperatures, samples were allowed to recover for $21 \mathrm{~h}$ at $26^{\circ} \mathrm{C}$ in darkness and subsequently in the indoor running seawater tank for $4 \mathrm{~d}$ under natural light shining through the glass roof windows $(16 \%$ reduction below ambient). Photochemical efficiency $\left(F_{\mathrm{v}} / F_{\mathrm{m}}\right)$ was measured immediately before the stress experiment and every third hour during the first $12 \mathrm{~h}$, every sixth hour during the next $12 \mathrm{~h}$ and then at the end of the $4 \mathrm{~d}$ recovery period. Aquaria for NT and HT treatments were placed at a room temperature $\left(26^{\circ} \mathrm{C}\right)$ in an air-conditioned room and aquaria for LT treatments were placed in a cold temperature $\left(10^{\circ} \mathrm{C}\right)$ room. Seawater temperatures were held at the desired temperatures using thermostat-regulated heaters (200 Watt, GEX). Illumination during the stress treatment was provided by metal halide lamps (Eye Clean Ace, IWASAKI) and photosynthetically active radiation (PAR) was measured using a quanta meter (LI-250, LI-COR). Small pieces were taken from the fragments before the stress experiment to identify the clades of zooxanthellae by the PCR-RFLP method described above.

Statistical analyses. All data were tested for normality and heteroscedasticity using Kolmogorov-Smirnov test and Bartlett's test, respectively. Monthly variations in photochemical efficiency and zooxanthellar density were analyzed using two-way mixed ANOVA (followed by post-hoc Bonferroni multiple comparison tests) where Month was analysed as a within-subject factor and Species was analysed as a between-subject factor. The sphericity assumption of errors was tested by Mauchly's sphericity test, and the Huynh-Feldt df adjustment (Huynh \& Feldt 1976) was applied when assumptions of the analyses were not met. $F_{\mathrm{v}} / F_{\mathrm{m}}$ data from stress treatments were analyzed by multiple comparison tests with Bonferroni adjustment. The MannWhitney U-test was used when $F_{\mathrm{v}} / F_{\mathrm{m}}$ values were compared between the two species in the stress experiments. All statistical analyses were conducted using SPSS v14.0 (SPSS). 


\section{RESULTS}

\section{Seawater temperature and accumulated daily radiation dose}

Seawater temperature obtained from loggers ranged from $17.4^{\circ} \mathrm{C}$ (28 January) to $34.1^{\circ} \mathrm{C}$ (4 July). Monthly average of seawater temperature ranged from $20.6^{\circ} \mathrm{C}$ (February) to $29.6^{\circ} \mathrm{C}$ (August) (Fig. 1). Monthly average of total daily solar radiation obtained from Okinawa Meteorological Observatory ranged from 7.36 MJ $\mathrm{m}^{-2} \mathrm{~d}^{-1}$ (February) to $22.4 \mathrm{MJ} \mathrm{m}^{-2} \mathrm{~d}^{-1}$ (July).

\section{Zooxanthellar clade}

PCR-RFLP of 18S-rDNA and 28S-rDNA indicated that Pavona decussata was associated only with clade $\mathrm{C}$ zooxanthellae irrespective of sampling time, while clade composition fluctuated in P. divaricata (Fig. 2). Three colonies of $P$. divaricata harbored clade D zooxanthellae throughout the year and the other 7 colonies changed zooxanthellar clade from $\mathrm{C}$ to $\mathrm{D}$ or vice versa, or contained zooxanthellae of both clades $\mathrm{C}$ and $\mathrm{D}$ at the same time. Colonies of $P$. divaricata harboring clade C zooxanthellae alone were not observed in July, September, October or November 2006. All P. divari-

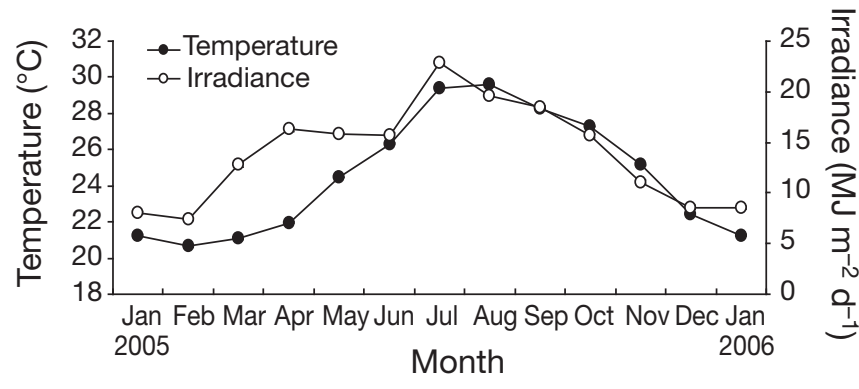

Fig. 1. Monthly mean daily seawater temperature and daily total irradiance ( $\mathrm{MJ} \mathrm{m}^{-2} \mathrm{~d}^{-1}$ ) from January 2005 to January 2006. Seawater temperature was logged at Bise, Okinawa, Japan, and data on accumulated daily irradiance were obtained from Okinawa Meteorological Observatory cata colonies examined harbored only clade D zooxanthellae in July and November 2006.

\section{Photochemical efficiency}

Significant interactions between month and species were observed for the $F_{\mathrm{v}} / F_{\mathrm{m}}$ ratios of Pavona divaricata and $P$. decussata (2-way ANOVA, Table 1), indicating

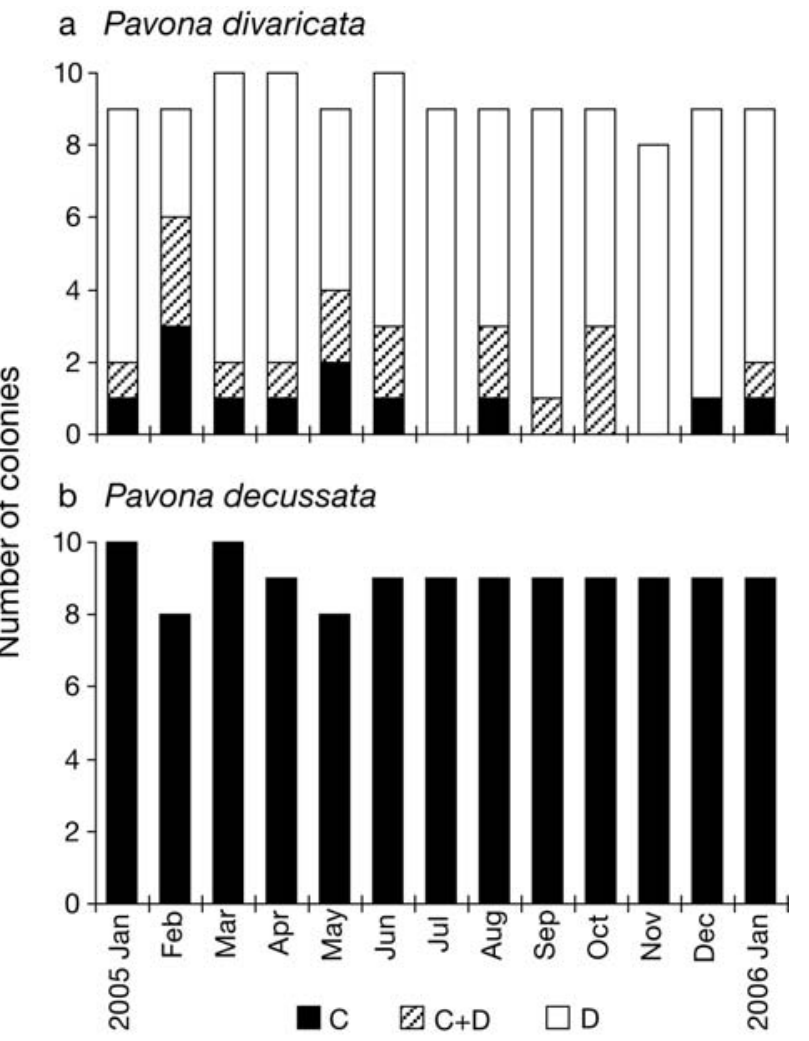

Fig. 2. Zooxanthellar clade composition in 10 tagged colonies of (a) Pavona divaricata and (b) P. decussata at Bise, Okinawa, Japan from January 2005 to January 2006. Results are from digestion of PCR products of nuclear 18S ribosomal DNA and nuclear $28 \mathrm{~S}$ ribosomal DNA by TaqI. Bars $<10$ colonies: loss of the tagged colony or samples

Table 1. Pavona divaricata and $P$. decussata. Two-way repeated measures ANOVA of photochemical efficiency $\left(F_{\mathrm{v}} / F_{\mathrm{m}}\right)$ of Photosystem II at Bise, Okinawa, Japan from January to December 2005. When there was a significant treatment effect at $\mathrm{p}<$ 0.05, post hoc tests (with Bonferroni adjustment procedure) were used to determine significant pairwise differences among treatment means

\begin{tabular}{|c|c|c|c|c|c|}
\hline Source of variation & df & MS & $F$ & $\mathrm{p}$ & Post hoc \\
\hline \multicolumn{6}{|l|}{ Within subjects } \\
\hline Month & 12.0 & 0.005 & 7.03 & $<0.001$ & Feb, Dec $>$ Mar, Jul, Aug; May $>$ Aug \\
\hline Month $\times$ Species & 12.0 & 0.002 & 2.57 & $<0.01$ & $\begin{array}{l}\text { P. divaricata > P. decussata for Mar, } \\
\text { Apr, Aug, Sep }\end{array}$ \\
\hline \multicolumn{6}{|l|}{ Between subject } \\
\hline Species & 1.00 & 0.010 & 5.68 & $<0.05$ & P. divaricata $>$ P. decussata \\
\hline
\end{tabular}


that the sampling month and the species interactively influenced the photochemical efficiency of algal PSII. Post hoc analysis indicated that the $F_{\mathrm{v}} / F_{\mathrm{m}}$ values in March and August were significantly lower than those in February and December in P. decussata (Bonferroni's post hoc test, $\mathrm{p}<0.05)$. No significant seasonal variation was observed in $P$. divaricata. Photochemical efficiency of $P$. decussata was significantly lower than that of $P$. divaricata in early spring (March to April) and summer (August to September) (Bonferroni's post hoc test, $\mathrm{p}<0.05$, Fig. 3 ). In the statistical tests described above, data for all colonies of $P$. divaricata were pooled regardless of zooxanthellar clade composition. When colonies of $P$. divaricata harboring clade $\mathrm{D}$ alone were analyzed, the same results were obtained. $P$. divaricata colonies that harbored clade C zooxanthellae alone showed seasonal fluctuation similar to that of P. decussata; colonies harboring both clade C and D zooxanthellae had a stable response to environmental changes, as did those harboring clade D zooxanthellae (Fig. 3). However, we could not test these tendencies statistically due to small numbers of $P$. divaricata colonies with clade $\mathrm{C}$ or with $\mathrm{C}$ and D.

In quadratic regression analyses, statistically significant relationships between monthly $F_{\mathrm{v}} / F_{\mathrm{m}}$ values and the monthly average of seawater temperatures were found for Pavona decussata $\left(\mathrm{r}^{2}=0.144, \mathrm{p}<0.001\right)$ and $P$. divaricata colonies harboring clade $\mathrm{C}$ zooxanthellae only $\left(\mathrm{r}^{2}=0.472, \mathrm{p}<0.05\right)$, but not for $P$. divaricata colonies harboring both clade $\mathrm{C}$ and $\mathrm{D}\left(\mathrm{r}^{2}=0.006, \mathrm{p}>\right.$ 0.05) (Fig. 4). Although the regression for P. divaricata harboring clade D was significant, $\left(\mathrm{r}^{2}=0.074, \mathrm{p}<0.05\right.$,
Fig. 4), each coefficient in the quadratic equation was non-significant ( $p>0.05)$.

There was no positive relationship between monthly $F_{\mathrm{v}} / F_{\mathrm{m}}$ values and monthly average daily total solar radiation ( $p>0.05$, quadratic regression). However, there was a significant negative correlation between monthly $F_{\mathrm{v}} / F_{\mathrm{m}}$ values and monthly average daily total solar radiation for Pavona decussata $\left(\mathrm{r}^{2}=0.150, \mathrm{p}<\right.$ $0.001)$, but not in P. divaricata ( $p>0.05)$. The 2 species had different responses to seasonal environmental fluctuations, with $P$. decussata and $P$. divaricata colonies harboring clade $C$ zooxanthellae alone being more sensitive to environmental changes than $P$. divaricata colonies harboring clade D alone or both clades $\mathrm{C}$ and D.

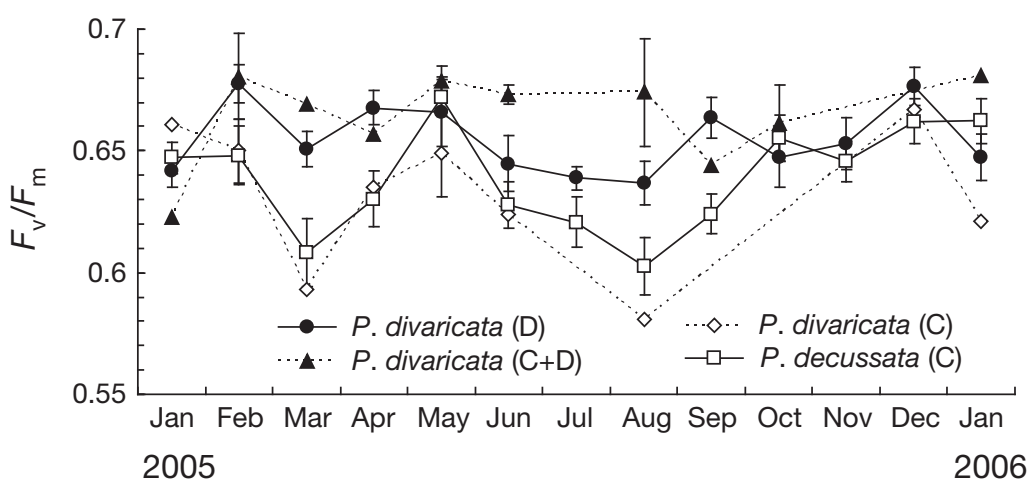

Fig. 3. Photochemical efficiency of algal Photosystem II $\left(F_{\mathrm{v}} / F_{\mathrm{m}}\right)$ in Pavona divaricata and P. decussata at Bise, Okinawa, Japan from January 2005 to January 2006. Means \pm SEM ( $n=8$ to 10$)$

\section{Zooxanthellar density}

Visible bleaching was not observed in either species at the study site at any time in the experimental period. Monthly measurements of zooxanthellar density supported this observation (Fig. 5). No significant relationship was found between zooxanthellar density and seawater temperature or light intensity. No significant interaction was found in the within-subject analysis of month (2-way ANOVA, Table 2), suggesting that sampling month did not influence zooxanthellar density 


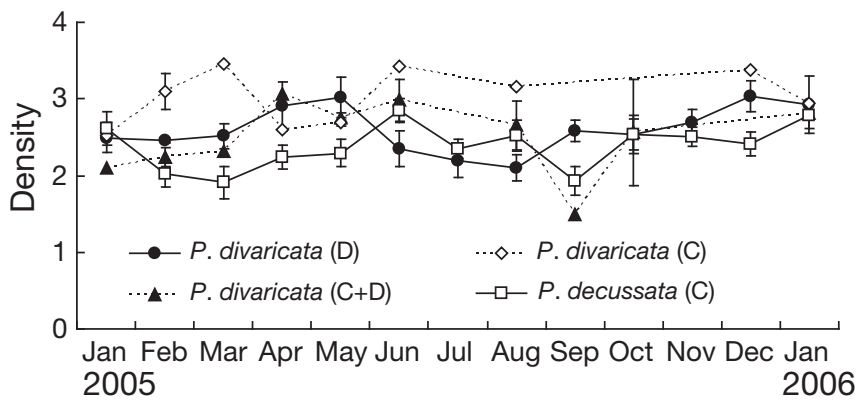

Fig. 5. Zooxanthellar densities $\left(\times 10^{6}\right.$ cells $\left.\mathrm{m}^{-2}\right)$ in Pavona divaricata and $P$. decussata at Bise, Okinawa from January 2005 to January 2006. Data are means \pm SE ( $=8$ to 10). Parentheses: zooxanthellar clade

during the experimental period. Between-subject analysis of species indicated that zooxanthellar density of Pavona divaricata was higher than that of P. decussata (2-way ANOVA, Table 2).

\section{Stress experiments}

There was no significant difference between the controls (NT+LL) in the experiment conducted on February 2005 and that on May 2006 (Mann-Whitney U-test, $\mathrm{p}>0.05)$. Accordingly, the data sets for the 2 control experiments were pooled. All samples of Pavona divaricata used for the stress experiments harbored clade D zooxanthellae, whereas P. decussata harbored clade $\mathrm{C}$.

Pavona divaricata had significantly higher $F_{\mathrm{v}} / F_{\mathrm{m}}$ values than $P$. decussata after the $3 \mathrm{~h}$ stress treatments except for the treatment combination with high temperature and light $(\mathrm{HT}+\mathrm{HL})$ (Mann-Whitney U-test, $\mathrm{p}<$ 0.05, Fig. 6). To compare the effects of various stress treatments in each species, multiple comparison tests with the Bonferroni adjustment were conducted. The tests demonstrated that the $3 \mathrm{~h}$ high light (HL) treat-

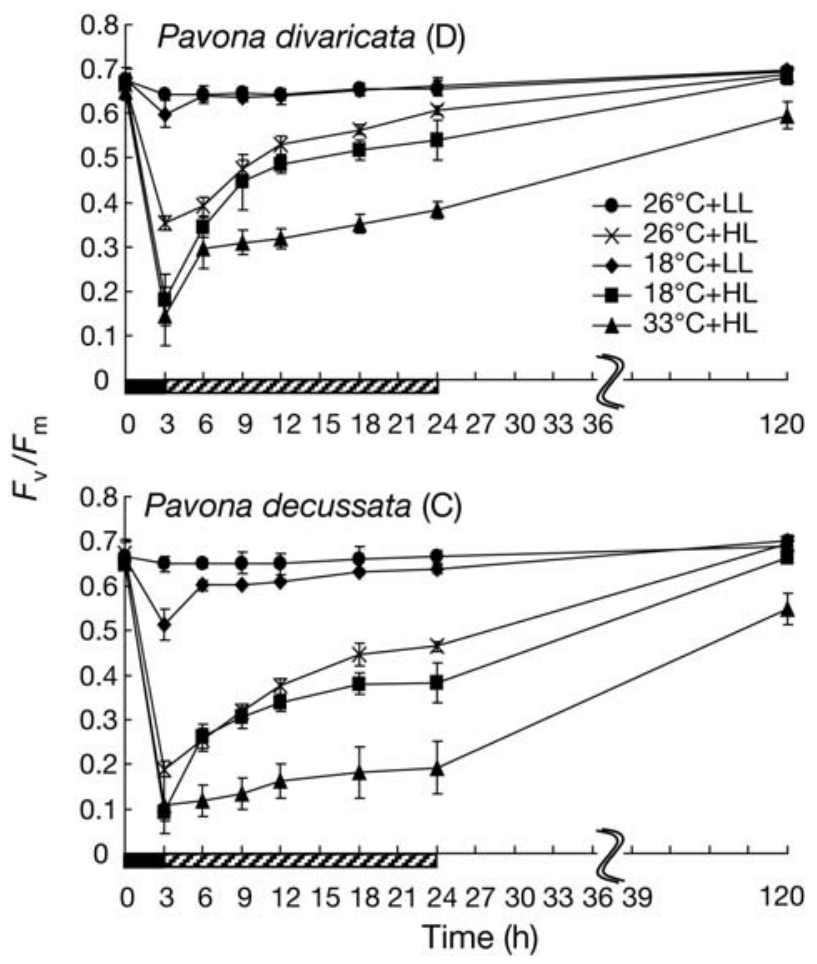

Fig. 6. The photochemical efficiency $\left(F_{\mathrm{v}} / F_{\mathrm{m}}\right)$ of algal PSII in Pavona divaricata and $P$. decussata (parentheses: zooxanthellar clade) before and after exposure to a combination of 3 temperature treatments $\left(26,18\right.$ and $\left.33^{\circ} \mathrm{C}\right)$ and 2 light regimes (LL: $100 \mu \mathrm{mol}$ photons $\mathrm{m}^{-2} \mathrm{~s}^{-1}$; and HL: $1000 \mu \mathrm{mol}$ photons $\mathrm{m}^{-2} \mathrm{~s}^{-1}$; black shading on $\mathrm{x}$-axis) for $3 \mathrm{~h}$, followed by a continuous (moderate) temperature of $26^{\circ} \mathrm{C}$ in darkness for $21 \mathrm{~h}$ (hatching on $x$-axis), and then allowed to recover (kept in a tank with running seawater under $84 \%$ natural light) for $4 \mathrm{~d}$. Data are means $\pm \mathrm{SD}(\mathrm{n}=5)$

ment lowered $F_{\mathrm{v}} / F_{\mathrm{m}}$ values significantly more than the low light (LL) treatment under all temperature conditions $(\mathrm{p}<0.05)$. The lowest $F_{\mathrm{v}} / F_{\mathrm{m}}$ values were recorded in both species after the $3 \mathrm{~h} \mathrm{LT}+\mathrm{HL}$ and $\mathrm{HT}+\mathrm{HL}$ treatments; the next lowest $F_{\mathrm{v}} / F_{\mathrm{m}}$ values occurred in the following NT+HL treatment $(\mathrm{p}<0.05)$. There was no significant difference after $3 \mathrm{~h}$ exposure between the

Table 2. Two-way repeated measures ANOVA of zooxanthellar density in Pavona divaricata and P. decussata at Bise, Okinawa, Japan from January to December 2005. df adj: Huynh-Feld df adjustment. When there was a significant effect at $\mathrm{p}<0.05$, post hoc tests were used to determine significant pairwise differences

\begin{tabular}{|c|c|c|c|c|c|c|}
\hline Source of variation & df & $\mathrm{df}_{\mathrm{adj}}$ & MS & $F$ & $\mathrm{p}$ & Post hoc \\
\hline \multicolumn{7}{|l|}{ Within subjects } \\
\hline Month & 12.0 & 10.8 & $6.01 \times 10^{11}$ & 1.70 & $0.09^{\mathrm{a}}$ & \\
\hline Month $\times$ Species & 12.0 & 10.8 & $4.64 \times 10^{11}$ & 1.31 & $0.23^{\mathrm{a}}$ & \\
\hline \multicolumn{7}{|l|}{ Between subject } \\
\hline Species & 1.00 & & $2.31 \times 10^{12}$ & 7.68 & $<0.05$ & P. divaricata $>$ P. decussata \\
\hline
\end{tabular}


control and the low temperature treatment under low light (LT+LL) in P. divaricata, whereas a significant difference was observed (between control and LT+LL treatment) in $P$. decussata $(\mathrm{p}<0.05)$.

$F_{\mathrm{v}} / F_{\mathrm{m}}$ values recovered from stress treatments in all cases. Pavona divaricata had significantly higher $F_{\mathrm{v}} / F_{\mathrm{m}}$ values than $P$. decussata after $3 \mathrm{~h}$ recovery at $26^{\circ} \mathrm{C}$ in darkness (Mann-Whitney U-test, $\mathrm{p}<0.05$, Fig. 6) except for the factor combination LT+HL. P. divaricata treated with $\mathrm{HT}+\mathrm{HL}$ for $3 \mathrm{~h}$ had a better $F_{\mathrm{v}} / F_{\mathrm{m}}$ recovery rate during the following $21 \mathrm{~h}$ period at $26^{\circ} \mathrm{C}$ in darkness than similarly treated $P$. decussata (Mann-Whitney U-test, p < 0.05, Fig. 6). After 4 d recovery in the indoor running seawater tank, $F_{\mathrm{v}} / F_{\mathrm{m}}$ values returned to almost pre-treatment levels in both species except for the $\mathrm{HT}+\mathrm{HL}$ groups. For the treatment combination $\mathrm{HT}+\mathrm{HL}$, there was a significant difference in $F_{\mathrm{v}} / F_{\mathrm{m}}$ between coral species at the end of the $4 \mathrm{~d}$ recovery.

\section{DISCUSSION}

We examined seasonal changes in maximum quantum yield of PSII $\left(F_{\mathrm{v}} / F_{\mathrm{m}}\right)$ and zooxanthellar clade composition simultaneously in 2 sympatric, congeneric corals Pavona divaricata and $P$. decussata on a highlatitude reef. The 2 species had different symbiotic partner flexibilities and responded differently to seasonal environmental fluctuations. P. decussata, which always contained clade $\mathrm{C}$ zooxanthellae, was more sensitive to seasonal environmental changes than $P$. divaricata, which was usually associated with clade D zooxanthellae, but also contained other clades (C alone, or a combination of $\mathrm{C}$ and $\mathrm{D}$ ).

In Pavona decussata, $F_{\mathrm{v}} / F_{\mathrm{m}}$ values fluctuated seasonally and declined significantly in early spring and summer. $P$. divaricata colonies harboring clade $\mathrm{C}$ zooxanthellae alone showed a similar seasonal fluctuation (Fig. 3). Although this similarity could not be statistically tested due to small number of $P$. divaricata colonies with clade $C$ zooxanthellae, $F_{\mathrm{v}} / F_{\mathrm{m}}$ values of $P$. decussata and $P$. divaricata colonies harboring clade $\mathrm{C}$ zooxanthellae alone decreased at both high and low temperatures (Fig. 4). In contrast, $F_{\mathrm{v}} / F_{\mathrm{m}}$ varied little seasonally in $P$. divaricata colonies harboring zooxanthellae of clade D or both clade C and D (Fig. 3). Results suggest that dinoflagellate symbiont type plays an important role in determining photophysiological responses of the holobiont to seasonal changes in environmental conditions.

Some corals harbor multiple genotypic clades of zooxanthellae, and zooxanthellar clade composition in them flucuates seasonally (Chen et al. 2005, Thornhill et al. 2006). In Pocillopora verrucosa and P. damicornis, colonies harboring clade D zooxanthellae are more tol- erant of high temperature stress than those harboring clade C zooxanthellae (Rowan 2004). Clade D zooxanthellae of Oulastrea crispata may also tolerate cold temperatures (Chen et al. 2003). Our study describes seasonal changes in photophysiology and zooxanthellar clade composition of 2 congeneric, sympatric corals simultaneously and showed, for the first time, that these corals differ in fidelity to symbiont type and respond differently to seasonal environmental changes.

The stress experiments also showed that Pavona divaricata colonies harboring clade D zooxanthellae were more tolerant to high or low temperature stress than $P$. decussata colonies harboring clade C zooxanthellae (Fig. 6). Association with clade D zooxanthellae might render $P$. divaricata tolerant to seasonal environmental changes, especially high temperature and high light stress in summer. From July to November 2005, when average seawater temperature was $>25^{\circ} \mathrm{C}$, most colonies were associated with clade D zooxanthellae and only one sample in August was found to harbor clade C zooxanthellae alone. Pavona divaricata is known as a stress tolerant species and has high recovery rates for both $F_{\mathrm{v}} / F_{\mathrm{m}}$ and maximum electron transport rates $\left(\mathrm{ETR}_{\max }\right)$ after temperature and light stresses (Yakovleva \& Hidaka 2004a). The coral also contains a high amount of Myc-Gly (a mycosporin-like amino acid, MAA, with an antioxidant function) in the host tissue (Yakovleva \& Hidaka 2004b). Since host corals may also play an important role in the stress tolerance of holobionts (e.g. Bhagooli \& Hidaka 2003), the role of host in the observed difference in the stress tolerance between two Pavona species remains to be studied.

Declines in dark-adapted $F_{\mathrm{v}} / F_{\mathrm{m}}$ are generally considered to reflect either short term dynamic photoinhibition known as photoprotection or long term chronic photoinhibition known as photodamage (Jones \& Hoegh-Guldberg 2001). The reduction of $F_{\mathrm{v}} / F_{\mathrm{m}}$ induced by down-regulation of PSII or by the function of the xanthophyll cycle is considered a photoprotective process and proceeds on a timescale of minutes (Gorbunov et al. 2001). Dynamic photoinhibition due to damage to the D1 protein in PSII recovers on a timescale of minutes to hours (Gorbunov et al. 2001), while chronic photoinhibition due to severe damage to PSII recovers much more slowly and is associated with coral bleaching (Warner et al. 1999, Jones \& HoeghGuldberg 2001). Because measurements of $F_{\mathrm{v}} / F_{\mathrm{m}}$ in our study were conducted in the morning (08:00 to 10:00 h) without exposure to full sunlight, observed seasonal declines of $F_{\mathrm{v}} / F_{\mathrm{m}}$ in Pavona decussata might be due to long term photoinhibition responses carried over from the previous days.

The $F_{\mathrm{v}} / F_{\mathrm{m}}$ values of Pavona decussata declined in March and August 2005. Biannual declines in $F_{\mathrm{v}} / F_{\mathrm{m}}$ 
observed in this study have not been reported in any other corals. This phenomenon may be a unique characteristic of this study area with a wide range of seasonal temperatures $\left(17.4\right.$ to $\left.34.1^{\circ} \mathrm{C}\right)$. The declines of $F_{\mathrm{v}} / F_{\mathrm{m}}$ in August might be due to high temperature and strong sunlight in the summer (Warner et al. 2002, Winters et al. 2006). Seawater temperature at the site of collection increased from February to August and monthly average daily seawater temperature exceeded $29^{\circ} \mathrm{C}$ in July and August (Fig. 1). Monthly average of daily recorded solar radiation rose from February to April and peaked in July after the rainy season (late May to late June). The $F_{\mathrm{v}} / F_{\mathrm{m}}$ decline in March might be due to cold seawater temperature accompanied by a sharp rise in light intensity. The photosynthetic apparatus of zooxanthellae that are acclimated to weak light might become inactivated by the increase in sunlight (Hoogenboom et al. 2006). The mechanism of photosynthetic inactivation induced by cold temperature in corals is thought to be similar to that induced by high temperature (Saxby et al. 2003). Severe coral bleaching by abnormally low seawater temperature occurs in high latitude coral populations in Kushimoto, Japan $\left(33^{\circ} 29^{\prime} \mathrm{N}, 135^{\circ} 46^{\prime} \mathrm{E}\right)$ (Nomura 2004) and on the southern Great Barrier Reef, Australia ( $\left.23^{\circ} 26^{\prime} \mathrm{S}, 151^{\circ} 55^{\prime} \mathrm{E}\right)$ (Hoegh-Guldberg et al. 2005).

The $F_{\mathrm{v}} / F_{\mathrm{m}}$ declines in our study were small, even in Pavona decussata. However, it is likely that greater anomalies in seawater temperature and light intensity will produce more prominent changes in $F_{\mathrm{v}} / F_{\mathrm{m}}$. Although no bleaching phenomenon was observed during the experiment, the seasonal fluctuations of $F_{\mathrm{v}} / F_{\mathrm{m}}$ values might reflect a photophysiological response of the coral to stresses that were below the threshold for bleaching; seasonal changes in $F_{\mathrm{v}} / F_{\mathrm{m}}$ could be useful in assessing the health and bleaching susceptibility of corals.

Pavona decussata has a wider distribution than P. divaricata in Japan (Veron 2000), though P. decussata from Okinawa has higher sensitivity to environmental changes. Six colonies of $P$. decussata collected from a higher latitude shallow (2.5 to $3.0 \mathrm{~m}$ in depth), non-reef area at Shirahama $\left(33^{\circ} 40^{\prime} \mathrm{N}, 135^{\circ} 21^{\prime} \mathrm{E}\right)$, Japan harbored only clade C zooxanthellae (authors' unpublished data). This suggests that $P$. decussata maintains its high fidelity to clade $\mathrm{C}$ zooxanthellae even at higher latitudes, though we cannot rule out the possibility that $P$. decussata colonies in different environments may associate with genotypically and physiologically different zooxanthellar genotypes. Further studies are necessary to understand the relationship between zooxanthellar genotypes and geographic distribution of corals at high latitudes.

In summary, the two sympatric Pavona species had different fidelities to symbiont types and different tol- erances to seasonal environmental changes. Pavona decussata, which was associated only with clade C zooxanthellae had biannual declines in the photochemical efficiency $\left(F_{\mathrm{v}} / F_{\mathrm{m}}\right)$. The seasonal $F_{\mathrm{v}} / F_{\mathrm{m}}$ fluctuation may reflect photophysiological response to stresses that potentially cause coral bleaching and might be a useful parameter for assessing bleaching susceptibility of corals. Biannual $F_{\mathrm{v}} / F_{\mathrm{m}}$ declines in $P$. decussata show that both high temperature in summer and low temperature in winter may be coral bleaching causal factors in high-latitude reefs.

Acknowledgements. We thank the staff of Sesoko Station, Tropical Biosphere Research Center, University of the Ryukyus, where part of this study was done. We are also thankful for helpful comments of anonymous reviewers. This study was supported by the 21st Century COE program of the University of the Ryukyus, and by the Sasagawa Scientific Research Grant from the Japan Science Society.

\section{LITERATURE CITED}

Berkelmans R, van Oppen MJH (2006) The role of zooxanthellae in the thermal tolerance of corals: a 'nugget of hope' for coral reefs in an era of climate change. Proc R Soc Lond B Biol Sci 273:2305-2312

Bhagooli R, Hidaka M (2003) Comparison of stress susceptibility of in hospite and isolated zooxanthellae among five coral species. J Exp Mar Biol Ecol 291:181-197

Buddemeier RW, Kleypas JA, Aronson RB (2004) Coral reefs and global change: potential contributions of climate change to stresses on coral reef ecosystems. Pew Center on Global Climate Change, Arlington, VA

Chen CA, Lam KK, Nakano Y, Tsai WS (2003) A stable association of the stress-tolerant zooxanthella, Symbiodinium clade D, with the low-temperature-tolerant coral, Oulastrea crispata (Scleractinia: Faviidae) in subtropical nonreefal coral communities. Zool Stud 42:540-550

Chen CA, Wang JT, Fang LS, Yang YW (2005) Fluctuating algal symbiont communities in Acropora palifera (Scleractinia:Acroporidae) from Taiwan. Mar Ecol Prog Ser 295: 113-121

Coles SL, Jokiel PL (1977) Effects of temperature on photosynthesis and respiration in hermatypic corals. Mar Biol 43:209-216

Fitt WK, Warner ME (1995) Bleaching patterns of four species of Caribbean reef corals. Biol Bull (Woods Hole) 189: 298-307

Genty B, Briantais JM, Baker NR (1989) The relationship between the quantum yield of photosynthetic electron transport and quenching of chlorophyll fluorescence. Biochim Biophys Acta 990:87-92

Glynn PW (1988) El Niño-Southern Oscillation 1982-1983: nearshore population, community, and ecosystem responses. Annu Rev Ecol Syst 19:309-345

Glynn PW, D'Croz L (1990) Experimental evidence for high temperature stress as the cause of El Niño coincident coral mortality. Coral Reefs 8:181-191

Glynn PW, Peters EC, Muscatine L (1985) Coral tissue microstructure and necrosis: relation to catastrophic coral mortality in Panama. Dis Aquat Org 1:29-37

Gorbunov M, Kolber ZS, Lesser MP, Falkowski PG (2001) Photosynthesis and photoprotection in symbiotic corals. Limnol Oceanogr 46:75-85 
Hoegh-Guldberg O (1999) Climate change, coral bleaching and the future of the world's coral reefs. Mar Freshw Res 50:839-866

Hoegh-Guldberg O, William MF, Johnstone SR, Dove S, Strong A (2005) Coral bleaching following wintry weather. Limnol Oceanogr 50:265-271

Hoogenboom MO, Anthony KRN, Connolly SR (2006) Energetic cost of photoinhibition in corals. Mar Ecol Prog Ser 313:1-12

Huynh H, Feldt LS (1976) Estimation of the Box correction for degrees of freedom from sample data in randomized block and split-plot designs. J Educ Stat 1:69-82

Jones RJ, Hoegh-Guldberg O (2001) Diurnal changes in the photochemical efficiency of the symbiotic dinoflagellates (Dinophyceae) of corals: photoprotection, photoinactivation and the relationship to coral bleaching. Plant Cell Environ 24:89-99

Jones RJ, Kerswell AP (2003) Phytotoxicity of photosystem II (PSII) herbicides to coral. Mar Ecol Prog Ser 261:149-159

Kerswell AP, Jones RJ (2003) Effects of hypo-osmosis on the coral Stylophora pistillata: nature and cause of 'lowsalinity bleaching'. Mar Ecol Prog Ser 253:145-154

Lesser MP (1996) Elevated temperatures and ultraviolet radiation cause oxidative stress and inhibit photosynthesis in symbiotic dinoflagellates. Limnol Oceanogr 41:271-283

Lesser MP (1997) Oxidative stress causes coral bleaching during exposure to elevated temperatures. Coral Reefs 16:187-192

Lesser MP, Gorbunov MY (2001) Diurnal and bathymetric changes in chlorophyll fluorescence yields of reef corals measured in situ with a fast repetition rate fluorometer. Mar Ecol Prog Ser 212:69-77

Lesser MP, Stochaj WR, Tapley DW (1990) Bleaching in coral reef anthozoans: effects of irradiance, ultraviolet radiation, and temperature on the activities of protective enzymes against active oxygen. Coral Reefs 8:225-232

Nakamura E, Yokohama Y, Tanaka J (2003) Photosynthetic activity of a temperate coral Acropora pruinosa (Scleractinia, Anthozoa) with symbiotic algae in Japan. Phycological Res 52:38-44

Nomura K (2004) Kii peninsula. In: The Japanease coral reef society and Ministry of the Environment (eds) Coral reefs of Japan. Ministry of the Environment, Tokyo, p 252-256

Pochon X, LaJeunesse T, Pawlowski J (2004) Biogeographic partitioning and host specialization among foraminiferan dinoflagellate symbionts (Symbiodinium, Dinophyta). Mar Biol 146:17-27

Rowan R (2004) Coral bleaching: thermal adaptation in reef coral symbionts. Nature 430:742

Editorial responsibility: Matthias Seaman, Oldendorf/Luhe, Germany
Rowan R, Powers DA (1991) Molecular genetic identification of symbiotic dinoflagellates (zooxanthellae). Mar Ecol Prog Ser 71:65-73

Santos SR, Taylor DJ, Kinzie RA, Hidaka M, Sakai K, Coffroth MA (2002) Molecular phylogeny of symbiotic dinoflagellates inferred from partial chloroplast large subunit (23S)-rDNA sequences. Mol Phylogenet Evol 23:97-111

Saxby T, Dennison WC, Hoegh-Guldberg O (2003) Photosynthetic responses of the coral Montipora digitata to cold temperature stress. Mar Ecol Prog Ser 248:85-97

Suwa R, Hidaka M (2006) Mechanism of zooxanthellae expulsion by corals: exposure to high temperature in darkness induces expulsion of zooxanthellae by coral hosts. In: Suzuki Y, Nakamori T, Hidaka M, Kayanne H and others (eds) Proc 10th Int Coral Reef Symp. Japanese Coral Reef Society, Tokyo, p 267-273

Tchernov D, Gorbunov MY, Vargas CD, Yadav SN, Milligan AJ, Haggblom M, Falkowski PG (2004) Membrane lipids of symbiotic algae are diagnostic of sensitivity to thermal bleaching in corals. Proc Natl Acad Sci USA 101: 13531-13535

Thornhill DJ, LaJeunesse TC, Kemp DW, Fitt WK, Schmidt GW (2006) Multi-year, seasonal genotypic surveys of coral-algal symbioses reveal prevalent stability or postbleaching reversion. Mar Biol 148:711-722

Veron JE (2000) Corals of the world, Vol 2. Australian Institute of Marine Sciences, Townsville

Warner ME, Fitt WK, Schmidt GW (1999) Damage to photosystem II in symbiotic dinoflagellates: a determinant of coral bleaching. Proc Natl Acad Sci USA 96:8007-8012

Warner ME, Chilcoat AGC, McFarland AFK, Fitt WK (2002) Seasonal fluctuations in the photosynthetic capacity of photosystem II in symbiotic dinoflagellates in the Caribbean reef-building coral Montastraea. Mar Biol 141: 31-38

> Winters G, Loya Y, Beer S (2006) In situ measured seasonal variations in $F_{\mathrm{v}} / F_{\mathrm{m}}$ of two common Red Sea corals. Coral Reefs 25:593-598

> Yakovleva I, Hidaka M (2004a) Differential recovery of PSII function and electron transport rate in symbiotic dinoflagellates as a possible determinant of bleaching susceptibility of corals. Mar Ecol Prog Ser 268:43-53

- Yakovleva I, Hidaka M (2004b) Diel fluctuations of mycosporine-like amino acids (MAAs) in shallow water scleractinian corals. Mar Biol 145:863-873

Zardoya R, Costas E, Lopez-Rodas V, Garrido-Pertierra A, Bautisa JM (1995) Revised dinoflagellate phylogeny inferred from molecular analysis of large-subunit ribosomal RNA gene sequences. J Mol Evol 41:637-645

Submitted: June 8, 2007; Accepted: December 11, 2007 Proofs received from author(s): May 27, 2008 